\title{
SPHERICAL CAP DISCREPANCY AND INEQUALITIES ON THE SPHERE
}

\section{MOHAMED AlLALI}

Abstract. The aim of this work is to present a method of covering the unit sphere by means of spherical caps of fixed radius. The method based on a set of rotations provides an explicit formula for the number of spherical caps that cover the whole unit sphere and the exact positioning of their centers.

Mathematics subject classification (2010): 26D05.

Keywords and phrases: Covering of the sphere, inequalities on the sphere.

\section{REFERENCES}

[1] A. LubotZKy, R. Phillips AND P. SARnAK, Hecke operators and distributing points on the sphere I, Comm. Pure Appl. Math., 39 (1986), 149-186.

[2] M. Allali, Compression on the digital sphere, Electron. J. Diff. Eqns., Conf. 07 (2001), 15-24.

[3] A. KiRILlov, Elements of the Theory of Representations, Springer-Verlag, New York, 1976.

[4] G. Szegö, Orthogonal Polynomials, AMS, Coll. Publ. XXIII, 1939.

[5] G. SzEGÖ, Über eine von Herrn S. Bernstein herrührende Abschätzung der Legendreschen Polynome, Math. Annalen, 108 (1933), 360-369.

[6] E. Rainville, Special Functions, MacMillan Company, New York 1960.

[7] D. Mitrinović, Analytic Inequalities, Springer, New York, 1970. 